\title{
A Study on Proposal of Flank Wear Criterion by Using a Built-in Current Sensor when Manufacturing the Mold Materials in a Smart Machine Tool
}

\author{
Seung-Yub Baek ${ }^{1, a}$, Sung-Taek Jung ${ }^{1}$, and Dae-Yu Park ${ }^{2}$ \\ ${ }^{1}$ Induk University, Department of Mechanical Design Engineering, Nowon-gu, Seoul, Republic of Korea \\ ${ }^{2}$ Hwacheon Machine Tool Co., Ltd, Gangseo-gu, Seoul, Republic of Korea
}

\begin{abstract}
Recently, it has been increased with respect to the safe and reliable operations in industry of machine tools and intelligent of the machine tool has consistently been developing in term of an unmanned manufacturing. For such realization, diagnosis monitoring of machining must be carried out while being processed in real-time. When tool wear is reached to criteria of flank wear and crater wear, the tools must be changed to new tools for improving the manless rate of operation. However, time of tool change was when spark generated because of wear about $0.3 \mathrm{~mm}$ on a flank face during manufacturing in the field. So, built-in sensor system in a smart machine tool must be necessary for high efficiency unmanned of manufacturing. As mentioned earlier, the various technique for measuring the tool wear was already defined such as sensing of acoustic emissions, vibrations, sounds, currents, cutting force, and other. The representative one of measuring method is current signal, which is used as a representative index of tool state. In this study, we carried out the proposal of tool wear criterion by using built-in wireless current signal system when manufacturing the mold materials of KP-4M and it was investigated via smart machine tools.
\end{abstract}

\section{Introduction}

Nowadays, competitive business environment, companies are facing as a goal with big data and developing decision-making algorithms for improving the productivity. Many manufacturers are trying to fuse with between previous machine tools such as a milling, turning, drilling and other, and smart system, which included big data, artificial intelligence and automation. To realizing the smart machine tools, it must be monitoring in real-time and self-diagnosing with respect to the core parts and tools. Especially, tool wear monitoring is one of the most important techniques to be developed for preventing tool breakage and improving the product quality.

Tool condition monitoring is essential to obtain good quality product and core parts. Also, tool wear monitoring techniques are classified as direct and indirect methods [1-2]. Direct methods measure real wear changes of cutting edge by machine vision [3] and scanning electron microscope (SEM) [4]. So, these methods are affected by mist, manufacturing environment, reflecting condition and condition of machine tools. On the other hand, indirect methods are such as acoustic emissions, vibrations, sounds, currents, cutting force, and they are utilizing as tool to diagnose the tool wear and machine tools and representative research case is an in the following.

Sadettin Orhan developed a monitoring system and tool wear evaluation methods by using a vibration

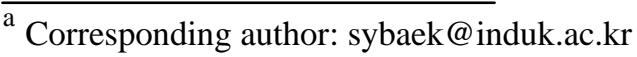

measurement when turning by end milling of AISI D3 cold work tool steel with 35HRC hardness [5]. The condition monitoring of milling tool was used to predict tool wear which is by linear relation via acoustic spectrum by C. S. Ai [6]. Also, Jun-Hong Zhou studied the measurement of tool wear using the acoustic emission from an embedded sensor for computation of features and prediction of tool wear [7]. However, previous methods are unsatisfactory because it can be checked after generating the wear or breakage.

To sensitively detect, in drilling process, Karali Patra [8] developed prediction model by regression model of flank wear through an artificial neural network based on the current signal. The measuring methods by the cutting force were developed for fault detection diagnosis based on an observer model of an uncertain linear system from [9]. But, these are not suitable for detecting both tool wear and machine tool conditions, and a built-in sensor is required to satisfy this. Among proposed sensing system, the monitoring of tool wear and machine tool is highly detected via built-in current sensors and flank wear can be determined by the current signal criterial.

In this study, we were able to propose the criterion with tool wear by using built-in current sensors and examined by using the measurement of two-dimensional image. In the future, it is necessary to develop algorithms suitable for diagnosing each case by built-in sensor system. 


\section{Experimental method}

The experiment method was carried out by the conditions which are utilizing the mold industry and test material is a KP-4M (150 $\mathrm{mm} \times 150 \mathrm{~mm} \times 150 \mathrm{~mm})$. Therefore, cutting condition has been mainly selected the suitable cutting speed and feed rate due to its high hardness of mold materials as shown in Table 1. Fig. 1 shows a change in the schematic illustration of the tool load during machining by getting the current signal transmit data. The experiment of tool wear was performed by using tools and workpiece and it indicated working distance and down milling method in Fig. 2. The insert tool type was decided as an experimental tool because end mill is very expensive than insert type tools. The wear characteristics were analyzed by this experiment in environment of dry condition without lubrication. The analysis was performed to show influences on tool wear characteristics by rough process. Finally, wear characteristics was investigated by using built-in current sensor and two-dimensional microscopes.

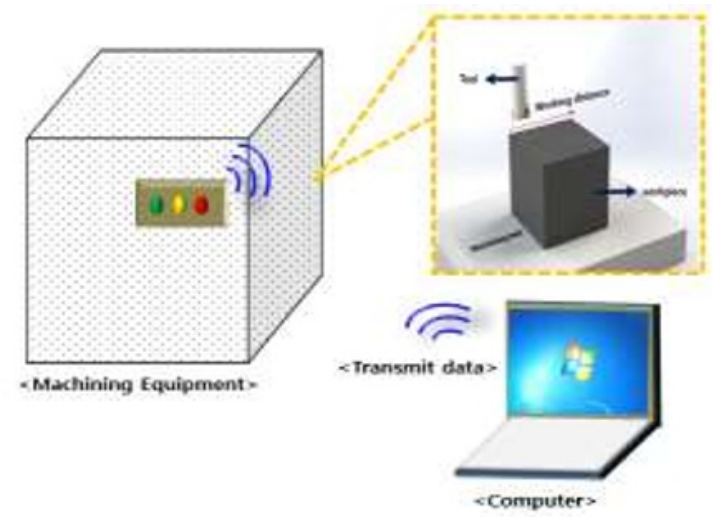

Fig. 1 Schematic illustration of gathering data of cutting load signal

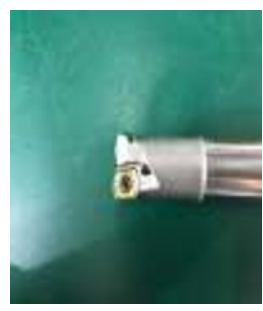

(a) Tool shape

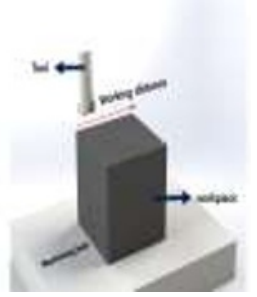

(b) Tool path: one-way

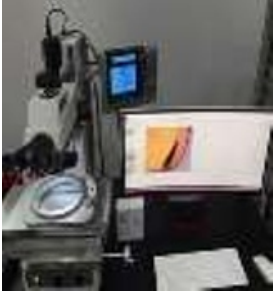

(c) Microscopes
Fig. 2 Photograph of tool geometry and experiment method for analyzing wear characteristics

Table 1. Cutting conditions of KP-4M.

\begin{tabular}{|c|c|c|c|}
\hline No & $\begin{array}{c}\text { RPM } \\
\left(\mathrm{min}^{-1}\right)\end{array}$ & $\begin{array}{c}\text { Feed } \\
(\mathrm{mm} / \mathrm{min})\end{array}$ & $\begin{array}{c}\text { Depth of cut } \\
(\mathrm{mm})\end{array}$ \\
\hline 1 & 6,700 & 6,000 & \multirow{2}{*}{0} \\
\hline 2 & 6,700 & 5,500 & \multirow{2}{*}{0.2} \\
\hline 3 & 5,400 & 6,000 & \multirow{2}{*}{} \\
\hline 4 & 5,400 & 5,500 & \\
\hline 5 & 4,800 & 6,000 & \\
\hline 6 & 4,800 & 5,500 & \\
\hline
\end{tabular}

\subsection{Tool wear characteristic analysis by using current signals}

We carried out analysis of the load signal with respect to its characteristics of the tool wear depending on built-in current signals as shown in Fig. 3. This paper were derived the correlation between tool wear and load signal. Tool wear normally is decided on criteria of $0.3 \mathrm{~mm}$ according to the international standard. So, we indicated the condition of tool wear from initial current signals to final current signals for deciding the tool life in wear zone. Because cutting speed is higher in case of 6,700 RPM, the current signals indicated high level due to increasing the coefficient of friction. Current signals continuously gathered until it reached to specific wear level. Especially, in case of condition 6, initial value of load signal is $5.5 \%$ because feed rate is lower than other cutting condition and increasing current load lead to the tool wear caused by forced thermal convection. Experiments of Previous tool wear needed worker to consistently check the tool condition in the field. Also, it must be reduced accessing to the machine tools in terms of unmanned manufacturing and the safety. In this experiment, we proposed the assessment criteria of tool wear by current signal reference and it was investigated. Results are as in the following. The current signal is about 6.5 to $7 \%$ in RPM 6,700 and is about 4.5 to $6 \%$ in RPM 5,400. Finally, the current signals are about 4.5 to $5 \%$ in RPM 4,800. These results showed that it has been experimentally verified that the higher the RPM, the higher the current signal level, which is directly related to tool life.

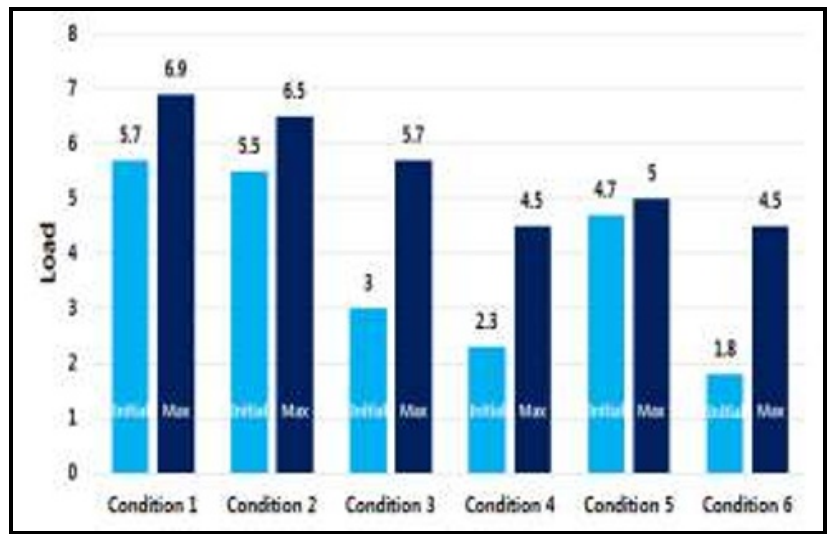

Fig. 3 Experimental results of tool wear characteristics with respect to the current signals

\subsection{Tool wear characteristic analysis by using two-dimensional microscopes}

The overall characteristics of tool wear were shown by using the two-dimensional microscope. The results of machining test were as in the following. As shown in Fig. 4,6 , tool wear with flank and crater and cutting time is indicated and these results by increasing the cutting speed had critical effects on the tool face because of its heat. Furthermore, the tear type chip is adsorbed onto cutting edge because of built-up edge. Their condition from 3 to 
6 was sensitively detected because cutting speed is lower than other condition. Also, the cutting time is comparatively improved in term of tool cost and however, the condition from 3 to 6 is slipped in view of product productivity. Latest trends are required improving the productivity efficiency. So, we were able to find the optimized cutting condition based on the experimental results. Moreover, behavior of tool wear was changed according to the materials and geometry of tool. Such conditions used in this experiment by built-in current sensor can very sensitively be detected with respect to the generating of wear by using rough process and mold materials. In the case of the characteristic of the tool wear, it is difficult to confirm all step because the characteristic change with respect to the heat sensitively occurs. Particularly, the tool wear characteristic of the nonlinear section may be different and the tool wear was observed in the linear section. We carried out characteristic analysis in terms of tool wear by the tool wear test time as shown in Fig. 5. And, as a result, we found the tool wear point by using current signal and criterion of flank wear proposed via our experiments without quantitative measurement.

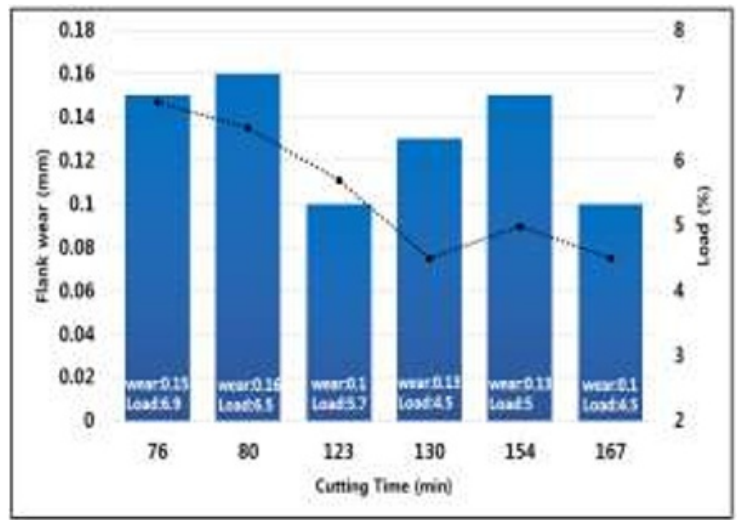

Fig. 4 Experimental results of tool wear characteristics in the time

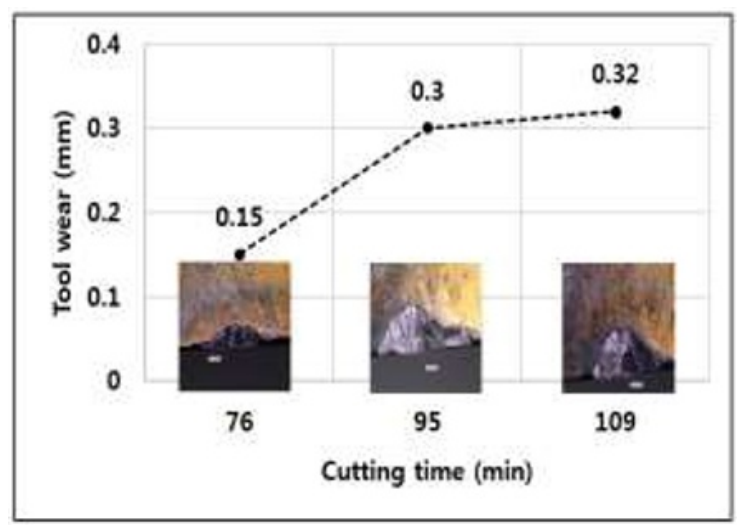

Fig. 5 Experimental results of tool wear characteristics in the time

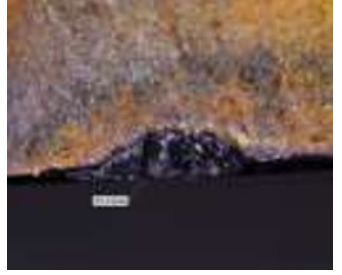

Flank wear : $0.15 \mathrm{~mm}$

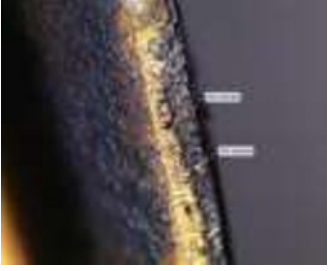

Crater wear $<$ Condition $1>$

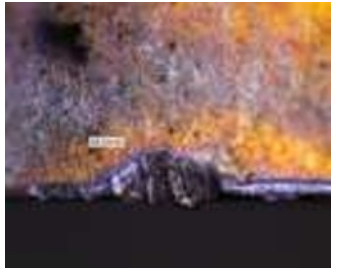

Flank wear : $0.16 \mathrm{~mm}$ $<$ Condition 2>

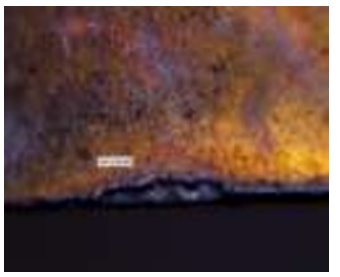

Flank wear : $0.1 \mathrm{~mm}$

$<$ Condition $3>$

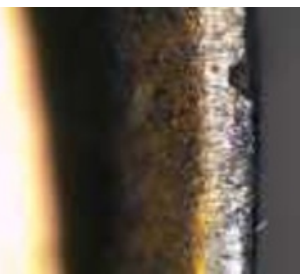

Crater wear

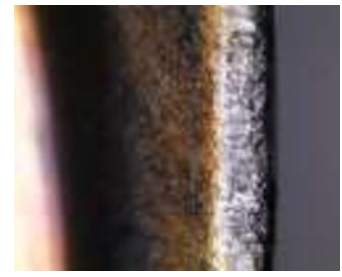

Crater wear

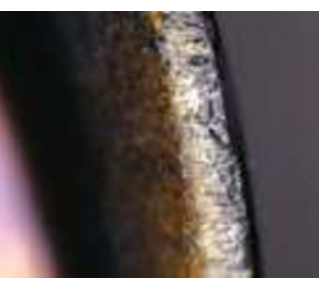

Crater wear

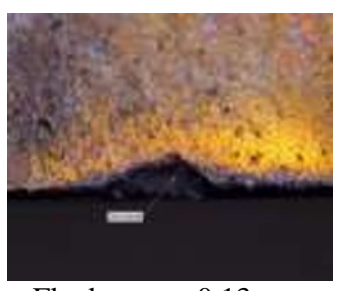

Flank wear : $0.13 \mathrm{~mm}$
$<$ Condition $4>$

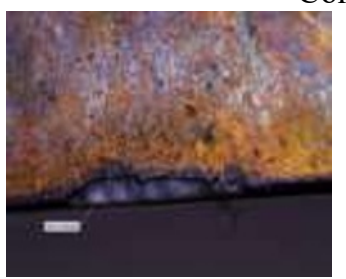

Flank wear : $0.15 \mathrm{~mm}$

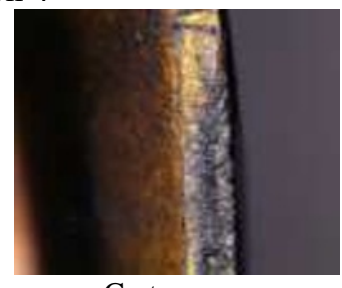

Crater wear

$<$ Condition 5 $>$

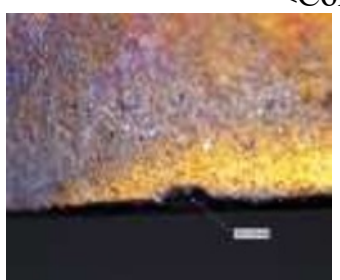

Flank wear : $0.1 \mathrm{~mm}$

$<$ Condition 6>

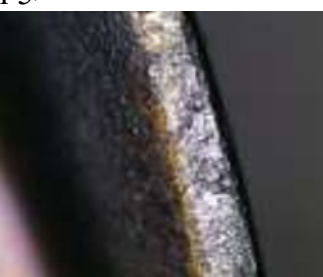

Crater wear
Fig. 6 Photograph of tool shape in microscopes

\section{Summary}

In this study, we presented a decision criteria that can predict the flank wear by using built-in current sensor, and they verified condition of flank wear due to its realtime monitoring by using two-dimensional microscopes. 
These experimental results showed that as the cutting speed increases, the load of the current signal increases, and the feed rate also tends to be similar. This is analyzed as the effect of increased frictional force due to the gradual rise of tool wear due to forced thermal convection. The specified criteria of this current signal became the guide line for flank wear, and the load gradually increased as the wear progressed. If the existing wear detection was performed directly by the dimensional microscopes, the current sensor could be installed inside the smart machine tools, allowing more sensitive evaluation than the existing one. This method can be used effectively because it depends on the amount of movement of the current level even if the cutting condition changes. Furthermore, built-in sensor systems had advantage. As s first, it is possible to monitor both tool condition and machine tools, second, it can notify to worker many information with respect to manufacturing situation. Finally, these manufacturing information will be piled up at a big data server and leading to information and communications technology and internet of things.

\section{Acknowledgements}

This work is supported by the Ministry of Trade, Industry and Energy Republic of Korea. (No. 10060188)

\section{References}

1. Haber, R. E., Jiménez, J. E., Peres, C. R., \& Alique, J. $\mathrm{R}$, An investigation of tool-wear monitoring in a high-speed machining process. ,Sensors and Actuators A: Physical, 116(3) 539-545 (2004).

2. N. Ghosh, Y. B. Ravi, A. Patra, S. Mukhopadhyay, S. Paul, A. R. Mohanty, A. B. Chattopadhyay, Estimation of tool wear during CNC milling using neural network-based sensor fusion. MSSP, 21(1), 466-479, (2007).

3. T. Pfeifer, L. Wiegers, Reliable tool wear monitoring by optimized image and illumination control in machine vision. Measurement, 28(3), 209-218, (2000)

4. M. Cabibbo, A. Forcellese, R. Raffaeli, M. Simoncini, Reverse engineering and scanning electron microscopy applied to the characterization of tool wear in dry milling processes. Procedia CIRP, 62, 233-238, (2017).

5. S. Orhan, A. O. Er, N. Camuşcu, E. Aslan, Tool wear evaluation by vibration analysis during end milling of AISI D3 cold work tool steel with 35 HRC hardness. NDT \& E International, 40(2), 121-126, (2007).

6. C. S. Ai, Y. J. Sun, G. W. He, X. B. Ze, W. Li, K. Mao, The milling tool wear monitoring using the acoustic spectrum. Int J Adv Manuf Technol, 61(5-8), 457-463, (2012).

7. J. H. Zhou, C. K. Pang, Z. W. Zhong, F. L. Lewis, Tool wear monitoring using acoustic emissions by dominant-feature identification. IEEE Transactions on instrumentation and measurement, 60(2), 547-559, (2011).
8. K. Patra, S. K. Pal, K. Bhattacharyya, Artificial neural network based prediction of drill flank wear from motor current signals. Applied Soft Computing, 7(3), 929-935, (2007).

9. S. N. Huang, K. K. Tan, Y. S. Wong, C. W. de Silva, H. L. Goh, W. W. Tan, Tool wear detection and fault diagnosis based on cutting force monitoring. International Journal of Machine Tools and Manufacture, 47(3-4), 444-451, (2007). 